\title{
Optical Sensor system for 3D measurements on large gears
}

\author{
Matthias Marcus Auerswald, Axel von Freyberg, Andreas Fischer \\ University of Bremen, BIMAQ - Bremen Institute for Metrology, Automation and Quality Science, \\ Linzer Str. 13, 28359 Bremen, \\ Email:m.mauerswald@bimaq.de
}

\begin{abstract}
:
Increasing demands require fast 3D geometric measurements of large gears with $\mu \mathrm{m}$ resolution, because detailed information regarding causes of geometrical deviations from the production process and the prediction of application properties, such as noise behavior, wear or material fatigue, are only possible by having accurate information about the gear geometry. As state of the art, pointwise tactile measurements are preferred, but the measurement rate is too low in particular for large gears. Optical sensors have the potential for fast multi-point measurements. However, the measurement at the convex and reflective surface of large metallic gears is challenging for optical sensor principles. For this purpose, a laser line triangulation sensor is investigated providing 1280 points at a line width of $25 \mathrm{~mm}$ with a depth resolution of $2 \mu \mathrm{m}$ and up to 2000 lines/s. As a result, 2.56 million measurement points can be acquired per second when employing a scanning. Measurement results at the tooth of a large gear with $956 \mathrm{~mm}$ diameter, a height of $246 \mathrm{~mm}$ and a module of $10 \mathrm{~mm}$ demonstrate the applicability of the sensor for fast geometric measurements with a lateral resolution of $19.5 \mu \mathrm{m}$. The laser line triangulation is qualified for fast three-dimensional measurements of the convex and reflective surface of large gears. The high measurement rate of 37,333 measurement points per second has been successfully applied in an optical scanning method for the measurement of a complete tooth flank of a large gear. In comparison with a tactile reference measurement, the measurement deviation amounts $19.8 \mu \mathrm{m}$.
\end{abstract}

Key words: large gears, laser line scanner, area oriented, geometric deviations, quality inspection

\section{Introduction}

Gear measuring instruments (GMI) and coordinate measuring machines (CMM, Fig. 4) with a tactile sensor system represent the gold standard for the quality testing of gearings where CMMs are offered in different designs [1]. The verification of the geometry in the standard tactile gear inspection is insufficient to improve the quality of the gears for certain applications, e.g., wind energy transmissions. Wind energy is an emerging technology, not only in the energy section but also in terms of production technology. Insurance statistics reveal that gearbox damages are a proximate cause of the possible damage to a wind power installation [2]. This is justified by the fact that the combination of large and changing loads with lightweight design requirements means that the gearboxes do not reach the planned service life. The causes of geometrical deviations from the production process and the prediction of application properties, such as noise behavior, wear or material fatigue, are only possible by having detailed information about the gear geometry.
Moreover, in industrial measurement technology, higher speeds are required with increasing flexibility in order to guarantee a $100 \%$ quality test. This is the reason why new optical measuring systems are required for the geometric measurement of objects to keep up with the increase in demands. Micro- and nanotechnology brings many measuring principles to physical limits. On the other hand, the area of large volume metrology is also a great challenge because of the increase in the required dynamic range of the measuring system. Tab. 1 shows the dimensions and tolerances in comparison between a large and a small gear.

Tab. 1: Dimensions and tolerances of large and small gears

\begin{tabular}{|c|c|c|}
\hline & $\begin{array}{c}\text { Large gear } \\
\text { (Wind energy) }\end{array}$ & $\begin{array}{c}\text { Small gear } \\
\text { (car) [3] }\end{array}$ \\
\hline Diameter d & $955 \mathrm{~mm}$ & $68 \mathrm{~mm}$ \\
\hline Weight $\mathrm{m}$ & ca.1.000 kg & $0.5 \mathrm{~kg}$ \\
\hline Total profile & $16 \mu \mathrm{m}$ & $6 \mu \mathrm{m}$ \\
\hline
\end{tabular}




\begin{tabular}{|c|c|c|}
\hline deviation $F_{\alpha}$ & & \\
\hline Module $\mathrm{m}$ & $10.0 \mathrm{~mm}$ & $1.7 \mathrm{~mm}$ \\
\hline Number of teeth $\mathrm{z}$ & 89 & 33 \\
\hline Pressure angle $\alpha$ & $20^{\circ}$ & $16^{\circ}$ \\
\hline Helix angle $\beta$ & $-15^{\circ}$ & $33^{\circ}$ \\
\hline Face width $\mathrm{b}$ & $246.0 \mathrm{~mm}$ & $17.3 \mathrm{~mm}$ \\
\hline
\end{tabular}

With regard to the diameter of the gearing, a measurement uncertainty is necessary for the evaluation of the total profile deviation $F_{\alpha}$ of large gears, which must be smaller by one order of magnitude than in case of small gears.

For more detailed assessment of the quality of the gears, a comprehensive inspection is required. However, the detection of the tooth geometry with tactile measuring systems is very time-consuming and also exorbitant in practice. Goch et al. came to the conclusion that hardly any improvements in the development of tactile measurement technology are to be expected [4]. Coordinate measuring machines (CMMs) are designed to perform only single measurements from a specified direction at a given time. The serial data acquisition with a single measurement point leads to an increase in measurement time, in particular for large components. Hence, a comprehensive quality assessment under economic aspects can only be carried out by faster optical sensors in combination with measurement concepts for parallel multi-point acquisition (array detection).

For this reason, the aim is to investigate the detection of convex and reflective threedimensional surfaces of large gears (see Fig. 1) by applying a laser line triangulation sensor. After a detailed review of the state of the art of large gear measurement techniques, the chosen sensor system and the experimental setup are described. Finally, the measurement results are presented and compared with a $\mathrm{CMM}$ reference measurement for determining the achievable accuracy.

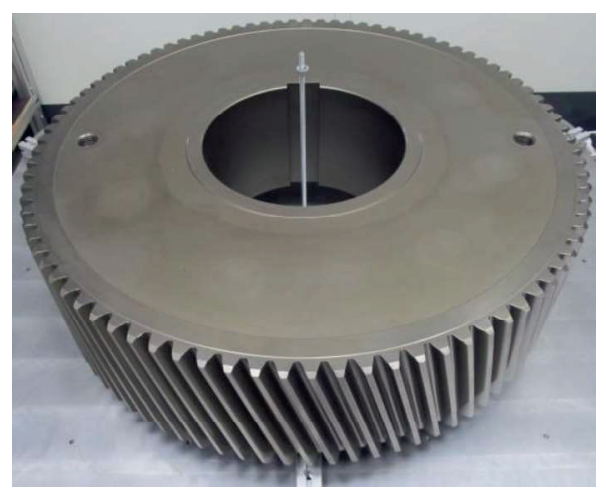

Fig. 1: Large gear with $956 \mathrm{~mm}$ in diameter, a height of $246 \mathrm{~mm}$ and a module of $10 \mathrm{~mm}$.

\section{State of the art}

CMMs of portal, bridge or stator construction are recommended for large components, whereas CMMs of the bridge design are recommended for gear testing and reach measuring volumes of $6.0 \times 4.5 \times 3.0 \mathrm{~m}^{3}$ [5].

The standard gearing test consists of the measurement of one profile and flank line on 3 or 4 teeth of the gear [6]. A single measuring point is additionally recorded on each tooth for evaluating pitch and runout deviations. This spot-check represents a compromise between measurement time and information content. This is justified by the fact that tactile measurement methods are used without exception in industrial practice. This hinders in particular the inspection of large gears while the demands are continuously increasing. The determinants for involute cylindrical gears and their deviations are defined in the standards [7]and [8]. For gear wheels which are used under high demanding conditions, e.g., in gearboxes of wind turbines, a more extensive test is recommended.

The tolerances for large gears start for the gear quality 5 at almost one hundredth of a millimeter [8] [9]. The evaluation of these tolerances places high requirements on the measurement technique that the standardization renounces compliance with the golden rule of the measuring technique. However, the development of large gear normals started only a few years ago [10] and corresponding calibration standards for gears with a diameter of more than $1 \mathrm{~m}$ are not commercially available. In the context of the requirements for a large dynamic range, short measuring time and the logistical effort, there are great challenges and approaches for the development of new measuring systems.

Tactile gear metrology has reached a state-ofthe-art, where significant improvements in terms of accuracy and velocity are hardly expected [4]. On the other hand, the most optical gear measurement approaches, which are area-oriented, are not accurate enough for the gear quality inspection task or only for special applications (stripe pattern projection for forged gears [11]), or they provide a sufficient uncertainty, but the acquisition of data is only point-wise (interferometric probe systems based on frequency modulation [12].

According to [4], triangulation methods provide a good basis for the detection of tooth flanks. Younes et.al. refer to the fact that laser triangulation sensors can be used for measuring gears [13]. In their approach, the required measurement uncertainty is not 
achieved to evaluate the tolerances of the tooth deflections, which is justified by the fact that the position deviations of the component cannot be separated from the influence of the axis of rotation with only one fixed sensor. However, the results do not disprove the basic suitability of this measuring principle for gear measurements. An advantage of this measuring principle is that it can be implemented in pointby-point, line wise [14]and even in the form of stripe pattern projections [15] or fringe reflection photogrammetry [16]. Depending on the implementation, a high data rate is possible and the measuring systems are quite insensitive to vibrations [17].

Today laser line scanners, i.e., laser line triangulation (LLT) sensors, are frequently used as an alternative for tactile probes on CMMs. In comparison with tactile probes, the main advantages are to measure without being in contact with the gear and also to capture many points in a short period of time. These characteristics predestine those sensors for capturing the surface of large gears. However, laser line scanners have a limited accuracy that depends strongly on the surface quality. It is difficult to measure shiny and reflective surfaces, e.g., the ground and hardened steel of gears, because diffuse reflection is needed in order to capture the projected laser line with the camera matrix. For large gears this principle has not been adequately tested, yet. An open question is whether a fast detection of convex and reflective three-dimensional surfaces of the tooth flank of large gears is possible by using a laser line triangulation sensor. Furthermore, the question arises whether this can lead to an increase in the measuring rate and how much is the resulting measurement error.

\section{Experimental setup}

The setup of a laser line scanner is depicted in Fig. 2a. Such a laser line scanner is used as an optical sensor system for the fast acquisition of the surface profile of a tooth flank, e.g. the profile, the helix as well as the tip and root of the teeth.

a

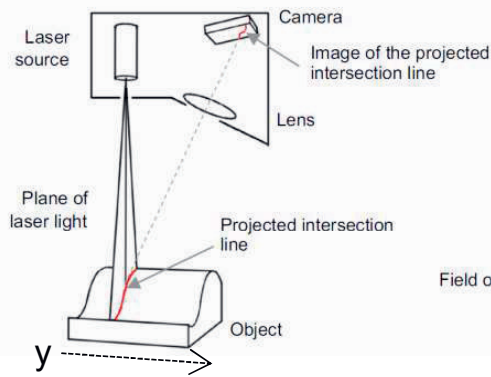

Fig. 2: Laser line scanning: (a) measurement principle; (b) resulting field of view [18].
The chosen sensor is of the type scanCONTROL 2910-25 from the company MICRO-Epsilon. It has a depth resolution of $2 \mu \mathrm{m}$ with 1280 points at a line width of $25 \mathrm{~mm}$, i.e. the lateral resolution amounts to $19.5 \mu \mathrm{m}$. The data rate depends on the required exposure time, but the maximum is 2000 lines/s. The trapezoidal field of view (cf. Fig. 2b) of the image matrix is $25 \mathrm{~mm}$ in $x$ direction and $25 \mathrm{~mm}$ in $z$ direction. The basic distance of the sensor from the gear amounts to $53.5 \mathrm{~mm}$. A photo of the investigated gear with a diameter of $956 \mathrm{~mm}$, a height of $246 \mathrm{~mm}$ and a module of $10 \mathrm{~mm}$ is shown in Fig. 1, and the geometrical parameters are listed in Tab. 1. The assembly of the laser scanner for the detection of a complete tooth side is shown in Fig. 3.

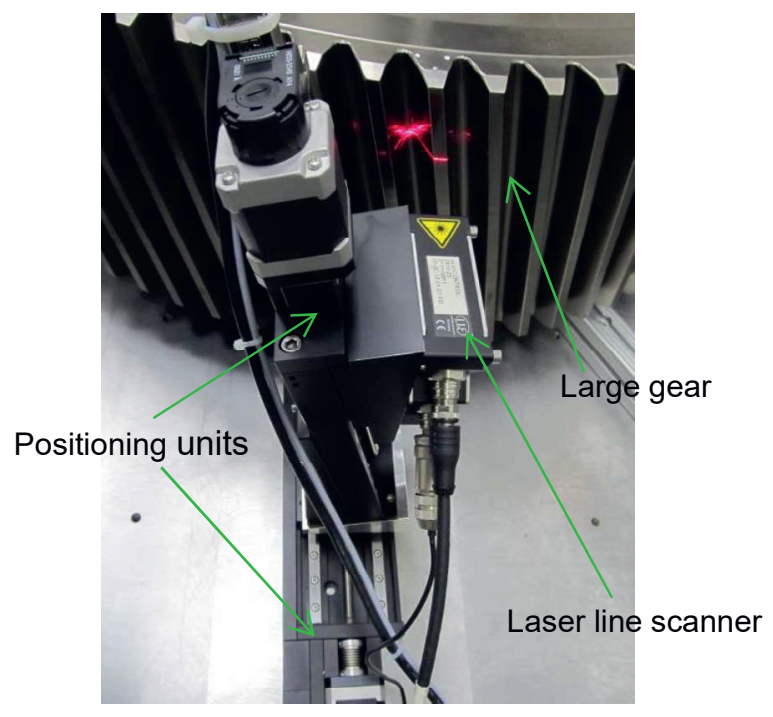

Fig. 3: Alignment of the laser scanner to the gearing.

The sensor detects the surface profile, which is located in its field of view (Fig. 2b). For the subsequent evaluation and assessment of the measurement deviation, the measurements of the sensor are compared with tactile reference measurements. These are obtained with a traceable CMM "Leitz PMM-F 30.20.7" from the Hexagon company (Fig. 4).

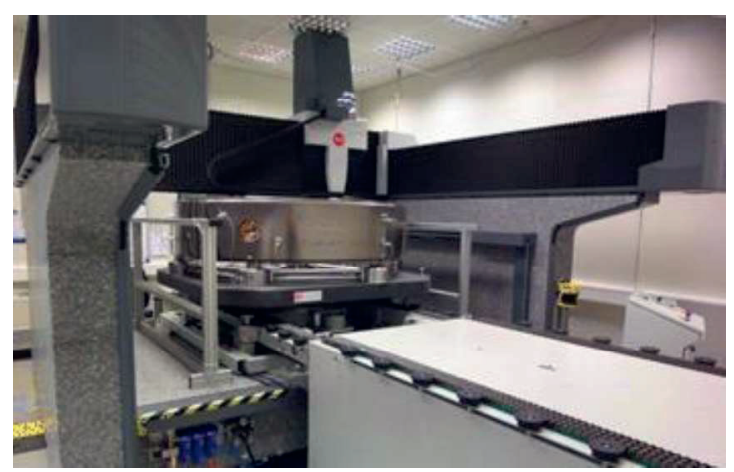

Fig. 4: CMM Leitz PMM-F 30.20.7 used for reference measurements. The shown measurement object is a large scale gear artifact. 
The reference measurement of the profile line was carried out with a tactile single point detection whereby the uncertainty of the CMM for length measurements is $\mathrm{MPE}_{E}=1.3 \mu \mathrm{m}+$ L/400 $\mu \mathrm{m} / \mathrm{mm}$ [5].

For the evaluation of the measurement error, a nominal-actual comparison is carried out. For this, the orthogonal distances of each measuring point (reference measurement with $\mathrm{CCM}$ and measurement with laser line scanner) to the nominal geometry (involute with geometry from Tab. 1) are calculated. The approximation of each point to the involute is performed by an iterative method for finding the minimum of the multivariate function whereby the "quasi-Newton method" represents the algorithm for numerical minimization.

In addition, it is intended to demonstrate the complete detection of the surface of a tooth flank. For this purpose, the complete tooth flank is scanned (see Fig. 3). The sensor is moved by a linear unit with stepper motor over the entire tooth width, has a fixed distance of 54 $\mathrm{mm}$ to the tip and moves at a constant speed.

\section{Results}

Fig. 5 shows all measurement points ( $x$ - and $z-$ coordinates) which are detected in the field of view of the sensor. The measuring frequency is $200 \mathrm{~Hz}$ (5 ms) for 1280 measurement points, which are detected simultaneously and thus parallel. It can be clearly seen that the detection of the complete surface profile of a tooth flank from the tip to the root at once is possible.

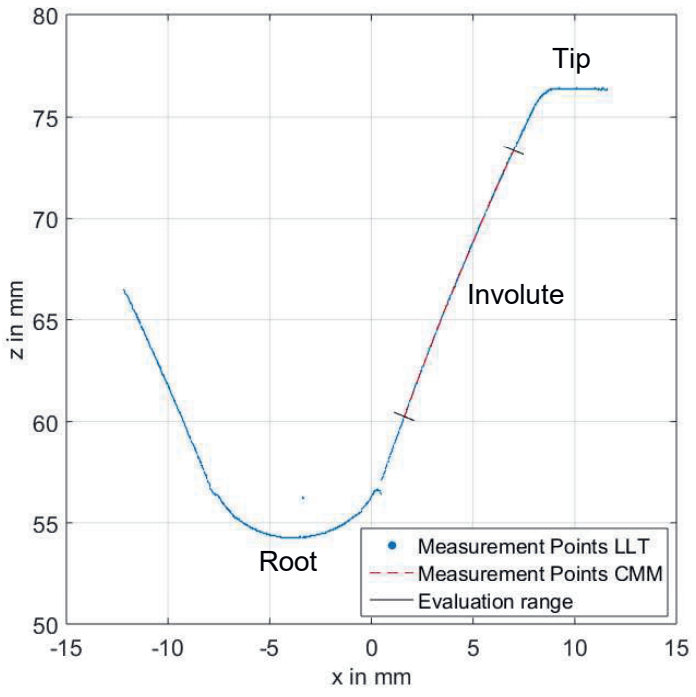

Fig. 5: A line of measurement points from the laser line triangulation.

An negligible region which cannot be detected is in the transition of the profile line into the root area. The reason is that multiple reflections occurs in this region, which disturbs the measurement. This effect must be taken into account and cannot be clearly distinguished by the sensor. However, the region is negligible since this region is not important for the functional inspection of a gear. The region of the profile line, which is of interest for the evaluation (evaluation range) is separated (see Fig. 5). In the experimental investigations, it could be observed that the orientation of the sensor has a direct influence on the appearing of multiple reflections. The projection of the laser line in the root area leads to the generation of multiple reflections (compare root area in Fig. 8). A part of these multiple reflections can be minimized by the usage of an aperture, which is attached at the tooth tip.

Fig. 6 shows the result of the approximation of the measurement points to the involute. In this case, the orthogonal distances $\left(d_{l o t}\right)$ of each measuring point of the laser line triangulation (LLT) and the reference measurement (CMM) to the ideal involute are shown.

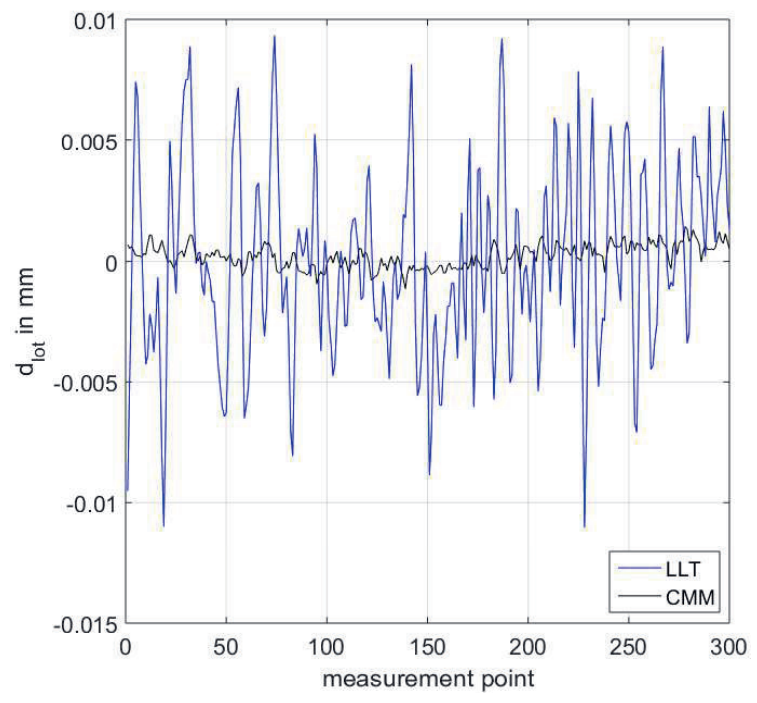

Fig. 6: Orthogonal distances ( $d_{l o t}$ ) of each measuring point (LLT and CCM) to the involute.

The two curves in Fig. 6 indicate the deviation between the extracted geometric element and the nominal geometric element which corresponds approximately to the total profile deviation $F_{\alpha}$.

Due to the low measurement uncertainty of the reference measurement, it is assumed that it represents the real geometry of the involute. Fig. 7 illustrates the direct comparison of the laser line measurements with the CMM measurements. It shows the difference (LLT$\mathrm{CMM}$ ) of the two graphical curves from Fig. 6 . 


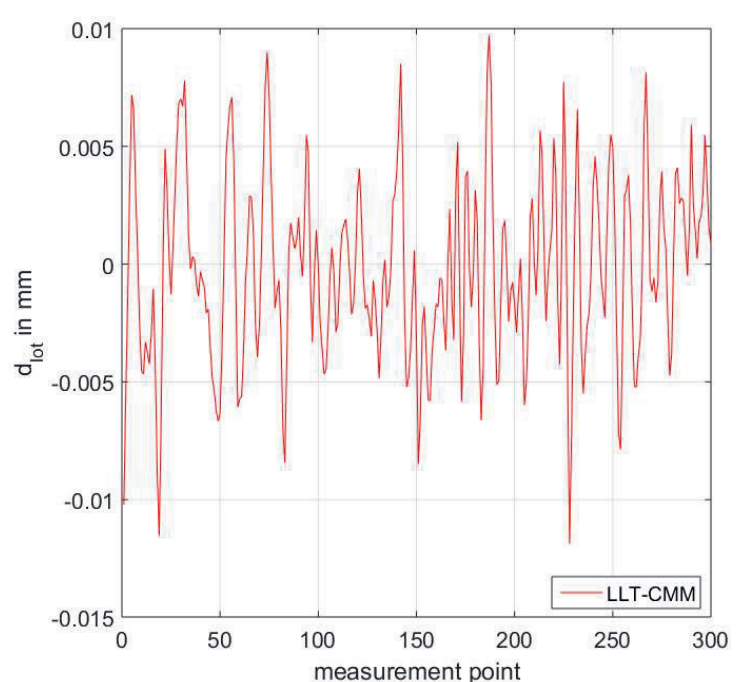

Fig. 7: Difference between the orthogonal distances of all points from both sensor systems to the involute.

The algebraic difference between the upper and the lower limit of the curve (spread) is given as the maximum measurement deviation. In relation to the golden standard, the deviation of the laser line triangulation amounts $19.8 \mu \mathrm{m}$. This deviation can be attributed to systematic and random measurement deviations. With regard to the present measurement deviation, it can be said that this is sufficiently small enough for the fast detection of the complete surface of the tooth flanks of large gears. However, for the evaluation of profile form deviations $f_{f \alpha}$ and profile slope deviations $f_{H \alpha}$ in a standard tooth quality inspection, the currently achieved deviation proves to be too high.

Fig. 8 shows the result of the linear scanning of the tooth flank by the sensor. The surface was detected by 3500 individual profile lines, which corresponds roughly to 4.48 million measurement points. The complete surface of one tooth flank was scanned from the tip to the root where the total section of measurements $(y$ component) corresponds to the face width of $246 \mathrm{~mm}$.

It can be clearly seen that the linear scanning of the complete surface of a tooth flank is possible. Due to the high and uniform number of measuring points on the entire surface, this can be displayed completely three-dimensional.

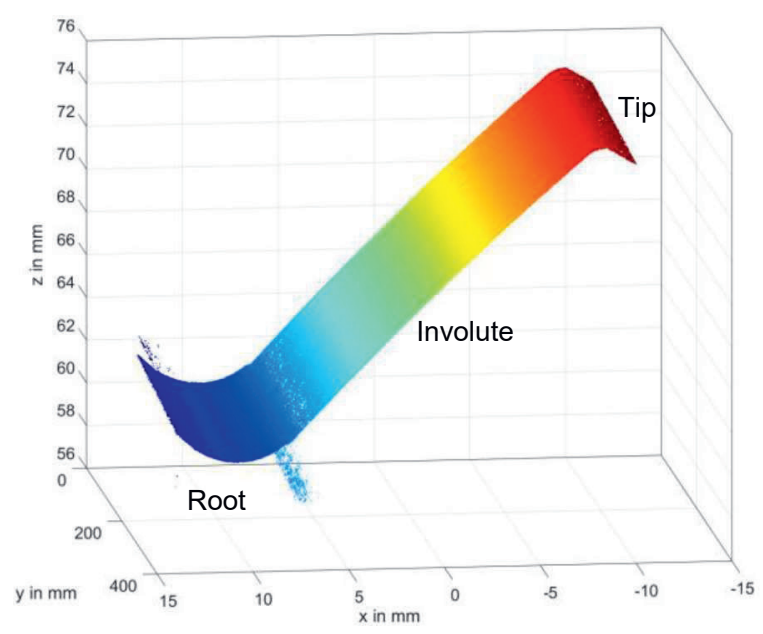

Fig. 8: Complete surface of one tooth flank of a large gear.

Moreover, the formation of the mentioned multiple reflections is visible in the root region. The complete scanning process with the laser line sensor amounts to 2 minutes. In a direct comparison to this, the measurement time for the tactile detection with the same point density would take 190 hours. It should be noted that a surface detection is the main focus of this application. This demonstrates clearly the considerable acceleration of an extensive measurement on large gears with the laser line triangulation with an acceleration factor of 5700 .

\section{Conclusion}

The results show, that the laser line triangulation is qualified for line-oriented acquisition of the convex and reflective surface of large gears. The fast and multi-dimensional detection of the total profile line is basically possible under the given boundary conditions. Regarding the temporal component, the laser line triangulation has a great advantage in contrast to the golden standard, since a measuring time of $<10 \mathrm{~ms}$ for one profile line is available with 1280 measuring points which are detected simultaneously. With regard to the measurement deviation of $19.8 \mu \mathrm{m}$, that it is sufficiently small enough for the rapid detection of the complete tooth surface of large gears. However, for the standard assessment of form and slope deviations, it is too high. Finally, the high measurement rate has been successfully applied in an optical scanning method for the three-dimensional measurement of a complete tooth flank of a large gear. 


\section{References}

[1] NORM DIN EN ISO 10360-1, 2003. Geometrische Produktspezifikation (GPS) Annahmeprüfung und Bestätigungsprüfung für Koordinatenmessgeräte (KMG) - Teil 1: Begriffe

[2] E. Bauer, F. Wikidal: Überblick über Schäden am mechanischen Strang von Windenergieanlagen, ATK (2005)

[3] C. Silbernagel: Beitrag zum Präzisionsschmieden von Zahnrädern für Pkw-Getriebe. Universität Hannover, Fachbereich Maschinenbau, Dissertation, 2003

[4] G. Goch: Gear metrology, Annals of the CIRP 52(2), 659-695 (2003); doi: 10.1016/S00078506(07)60209-1

[5] Hexagon Metrology: Produktbroschüre Leitz PMM-F / PMM-G. 05/2014

[6] Richtlinie VDI/VDE 2607, 2000.

Rechnerunterstützte Auswertung von Profil- und Flankenlinienmessungen an Zylinderrädern mit Evolventenprofil

[7] NORM DIN ISO 21771, 2014. Zahnräder Zylinderräder und Zylinderradpaare mit Evolventenverzahnung - Begriffe und Geometrie.

[8] NORM DIN EN ISO 1328-1, 1997, Cylindrical gears - ISO system of accuracy Part 1 : Definitions and allowable values of deviations relevant to corresponding flanks of gear teeth.

[9] NORM DIN 3962, 1978. Toleranzen für Stirnradverzahnungen.

[10] F. Härtig, H. Lin, K. Kniel, Z. Shi: Standard conforming involute gear metrology using an articulated arm coordinate measuring system. Measurement Science and Technology 23, Nr. 10 (2012)

[11] K. Meeß, M. Kästner, J. Seewig: Verringerung und Abschätzung der Messunsicherheit bei der optischen Verzahnungsmessung mit Streifenprojektion, tm - Technisches Messen 73, Nr. 11, 603-610 (2006); doi: 10.1524/teme.2006.73.11.60

[12] F. Balzer, M. Schäfer, I. Lindner, A. Günther, D. Stöbener, J. Westerkamp: Recent advances in optical gear measurements - A new approach for fast measurements of large gears, International Conference on Gears, VDI-Berichte 2255, 655666 (2015)

[13] M. A. Younes, A. M. Khalil, M. N. Damir: Automatic measurement of spur gear dimensions using laser light, part 2: measurement of flank profile. Optical Engineering 44, Nr. 10, 1036031 1036037 (2005)

[14] J. Chow, T. Xu, S. Lee, K. Kengkool: Development of an Integrated Laser-Based Reverse Engineering and Machining System. The International Journal of Advanced Manufacturing Technology 19, Nr. 3, 186-191 (2002)

[15] S. Zhang: Recent progresses on real-time 3D shape measurement using digital fringe projection techniques. Optics and Lasers in Engineering 48, Nr. 2, 149-158 (2010)

[16] Y.-L. Xiao, X. Su, W. Chen, Y. Liu: Threedimensional shape measurement of aspheric mirrors with fringe reflection photogrammetry. Applied Optics 51, Nr. 4, 457-464 (2012)

[17] G. Peggs, P. G. Maropoulos, E. Hughes, A. Forbes, S. Robson, M. Ziebart, B. Muralikrishnan: Recent developments in large-scale dimensional metrology. Proceedings of the Institution of Mechanical Engineers, Part B: Journal of Engineering Manufacture 223, Nr. 6, 571-595 (2009)

[18] N. Van Gestel, S. Cuypers, P. Bleys, J.-P. Kruth: A performance evaluation test for laser line scanners on CMMs, Optics and Lasers in Engineering 47, 336-342 (2009); doi: 10.1016/j.optlaseng.2008.06.001 